\title{
Other Building and Grounds Cleaning and Maintenance Workers
}

National Cancer Institute

\section{Source}

National Cancer Institute. Other Building and Grounds Cleaning and Maintenance

Workers. NCI Thesaurus. Code C122536.

Building and grounds cleaning and maintenance workers not specifically identified elsewhere. 